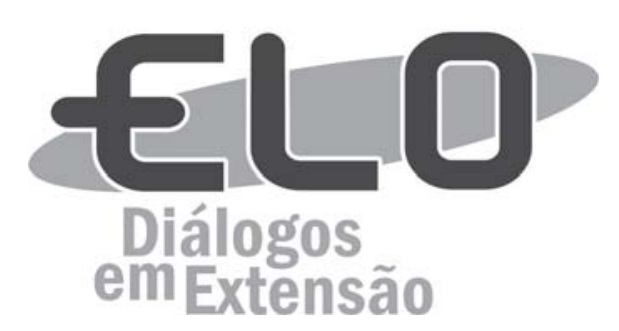

\title{
Coral Cênico UFVJM: um espaço de arte e formação acadêmica
}

José Rafael Madureira', Joyce Amanda dos Santos²

\begin{abstract}
Resumo: O presente trabalho é um relato de experiência do projeto de extensão universitária intitulado "Coral Cênico UFVJM". Temos como propósito oferecer à comunidade acadêmica um espaço de estudo e prática do canto coral com ênfase na encenação teatral. O projeto acolhe estudantes, técnicos e professores da UFVJM, como também membros da comunidade externa. Utilizamos uma metodologia ativa inspirada nos pressupostos estético-pedagógicos de Jaques-Dalcroze. Excetuando-se o trabalho de técnica vocal, todo processo é realizado através de exercícios e jogos corporais, o que favorece significativamente a assimilação dos conceitos musicais envolvidos como também a afinação do coro e sua percepção harmônica. O projeto tem apenas dois anos de vida e já dispõe de um substancial repertório a duas, três e quatro vozes, peças entoadas em português, inglês, espanhol, alemão e dialeto Zulu, o que revela a transnacionalidade inerente aos ambientes de formação musical.
\end{abstract}

Palavras-chave: Canto coral. Metodologias de Ensino de Música. Artes cênicas. Extensão. Cultura.

Área Temática: Educação e Cultura.

\section{Coral Cênico UFVJM: a space of art and academic education}

\begin{abstract}
The present work is an experience report of the project of university extension called "Coral Scenic UFVJM". We aim to offer the academic community a space for study and practice of choral singing with an emphasis on theatrical performance. The project welcomes students, technicians and teachers of the UFVJM, as well as members of the external community. We use an active methodology inspired on JaquesDalcroze's Eurythmics principles. Except for vocal training exercises, all process is conducted through body exercises and theatrical games, which significantly contributes to the development of musical skills, including vocal tuning and harmonic perception from the chorus. The project is only two years old and already has a substantial repertoire for two, three and four voices, musical pieces sung in Portuguese, English, Spanish, German and Zulu dialect, which reveals the inherent transnationality of musical education environments.
\end{abstract}

Keywords: Choral Singing. Methodologies of Music Teaching. Performing arts. University Extension, Culture.

\section{Coral Cênico UFVJM: un espacio de arte y formación académica}

Resumen: El presente trabajo es un relato de experiencia del proyecto de extensión universitaria titulado "Coral Cénico UFVJM". Tenemos como propuesto ofrecer a la comunidad académica un espacio de estudio y práctica del canto coral con énfasis en la escena teatral. El proyecto acoge a estudiantes, técnicos y profesores de la UFVJM, así como a miembros de la comunidad externa. Utilizamos una metodología activa inspirada en los presupuestos pedagógicos creados por Jaques-Dalcroze. Con excepción de los ejercicios de entrenamiento vocal, todo proceso se realiza a través de ejercicios y juegos corporales, lo que contribuye significativamente al desarrollo de las habilidades musicales, incluida la afinación vocal y la percepción armónica del coro. El proyecto tiene sólo dos años de vida y ya dispone de un sustancial repertorio a dos, tres y cuatro voces,

\footnotetext{
${ }^{1}$ Doutor em Educação (UNICAMP) e professor junto ao Departamento de Educação Física da Universidade Federal dos Vales do Jequitinhonha e Mucuri. Endereço: Rodovia MGT 367 - Km 583, n 5000. Alto da Jacuba, Diamantina - MG - CEP. 39.100-000 Telefone: (38) 9 8829-1819 E-mail: jr.madureira@ufvjm.edu.br

${ }^{2}$ Bacharel em Humanidades (UFVJM), graduanda em história e bolsista Procarte (PROEXC/UFVJM). E-mail: joyceufvjm@gmail.com
} 
piezas entonadas en portugués, inglés, español, alemán y dialecto Zulu, lo que revela la transnacionalidad inherente a los ambientes de educación musical.

Palabras clave: Canto Coral. Metodologías de la enseñanza de la música. Artes Escénicas. Extensión Universitaria. Cultura.

\section{Apresentação}

Para Villa-Lobos (1987, p.13): “Um povo que sabe cantar está a um passo da felicidade; é preciso ensinar o mundo inteiro a cantar". A sentença encerra alguma controvérsia, mas nos inspirou a conceber o projeto Coral Cênico UFVJM, uma ação extensionista registrada na Pró-Reitoria de Extensão e Cultura da Universidade Federal dos Vales do Jequitinhonha e Mucuri (campus Diamantina/MG) e contemplada 3 vezes pelo Programa de Bolsas de Apoio à Cultura e à Arte (editais 001/2015, 001/ 2016 e 001/2017).

O projeto Coral Cênico UFVJM foi escrito em consonância com as Metas do Plano Nacional de Cultura, destacando-se a meta $n^{\circ} 19$ e a meta $n^{\circ} 22$. Conforme a meta $n^{\circ} 19$ (BRASIL, 2012, p. 62): “O apoio à pesquisa acadêmica ou de linguagem torna possível desenvolver o conhecimento no campo da cultura, das linguagens artísticas e do patrimônio cultural". Já a meta $\mathrm{n}^{\circ} 22$ aponta para a valorização e o incentivo de grupos e coletivos locais, pois "[...] são espaços privilegiados para a experimentação e inovação tanto amadora como profissional. Além disso, são lugares nos quais as manifestações artísticas podem ser divulgadas e a diversidade cultural, valorizada." (ibidem, p. 68).

Nosso maior propósito é proporcionar aos participantes um espaço de estudo e prática do canto coral com ênfase na encenação teatral. Sabemos que, com um ensaio semanal de 90 minutos, não conseguiremos alcançar elevados níveis de performance musical, mas acreditamos que esse tempo é suficiente para realizarmos um trabalho artístico, honesto e de qualidade.

Temos como público-alvo os universitários, pois acreditamos na extensão como um espaço privilegiado de troca e abertura para novas concepções de educação e formação profissional. Mário de Andrade já dizia que "A cultura é tão necessária como o pão" (ANDRADE, 2005, p. 269). Assim, desejamos contribuir com a formação cultural dos futuros educadores, farmacêuticos, enfermeiros, médicos, geógrafos, dentistas, historiadores e engenheiros que arriscaram fazer parte do projeto. Por essa razão, desenhamos um perfil jovem, que varia de 18 a 29 anos. A faixa etária definida não é um impedimento para que "jovens" com mais 29 anos participem do projeto, afinal, temos vários coralistas que se encaixam nessa última categoria.

Além dos estudantes, também recebemos professores, técnicos administrativos, terceirizados e membros da comunidade de Diamantina e região que tenham alguma experiência em canto coral.

É importante mencionar que o projeto Coral Cênico UFVJM é um desdobramento no campo da extensão das atividades de pesquisa do Grupo de Estudos em Métodos e Técnicas de Ensino de Dança, Teatro e Música (CNPq/UFVJM).

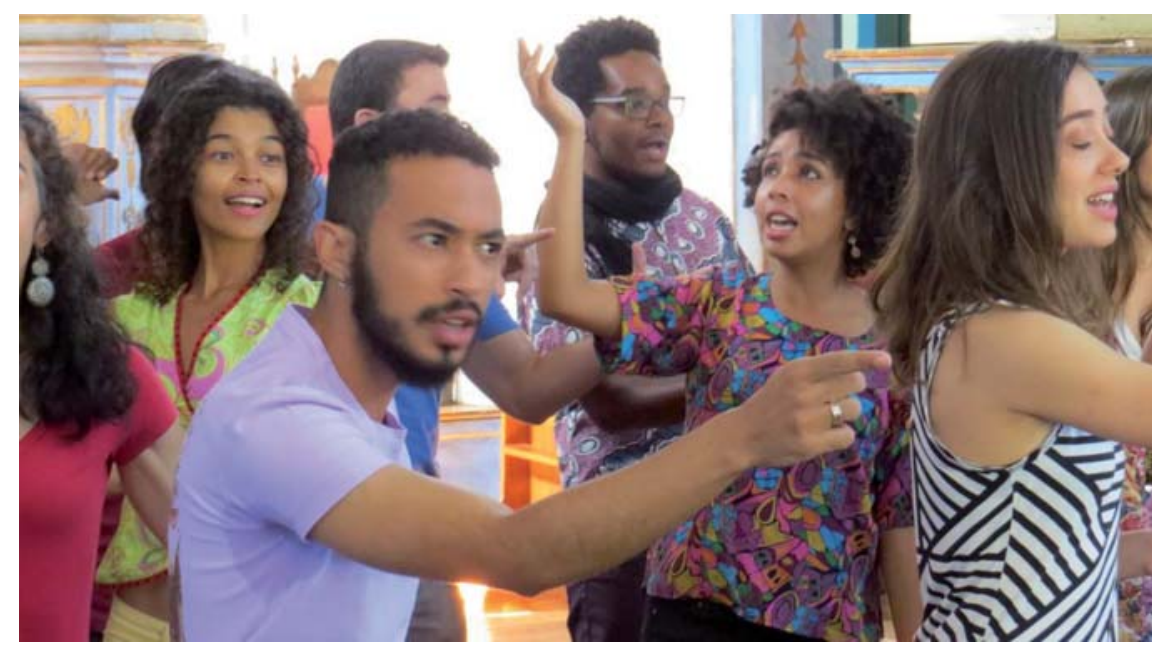

Figura 1 - Recital do Coral Cênico UFVJM realizado na Igreja do Rosário (Diamantina/MG, 17/07/2016) Fonte: Acervo pessoal dos autores 


\section{Pressupostos teórico-pedagógicos}

O canto coral é uma arte independente. Todavia, desde as reformas musicais instauradas pelos "pedagogos ativos" como Dalcroze, Willems, Orff e Kodály, o canto coral tem sido utilizado como uma importante ferramenta pedagógica na formação musical de crianças, jovens e adultos (FONTERRADA, 2008). Não por acaso, o canto coral é um componente curricular obrigatório em todos os conservatórios estaduais de música de Minas Gerais, do ciclo inicial ao ciclo complementar.

Para Renée Fleming (apud FEDERICI, 2009, p. 7): “É um milagre que alguém aprenda como cantar bem devido ao mistério de coordenar músculos involuntários, o que parece impossível de se esclarecer". Realmente, como toda arte, o canto encerra alguns mistérios, mas com um pouco de orientação e prática, é possível fazer um uso consciente dos recursos expressivos da voz e conquistar significativos resultados musicais.

A condução pedagógica de um coral precisa ser muito precisa, em especial, diante de grupos inexperientes, ou seja, pessoas que nunca receberam uma educação musical propriamente dita e que não possuem consciência do aparelho fonador, das técnicas de respiração e do alinhamento corporal (ZANDER, 2006).

De acordo com AMATO (2007, p.78-79), o líder de um coro deverá agir não somente na dimensão técnica do trabalho, mas também na administração social e afetiva dos coralistas. Vale destacar que o trabalho desenvolvido em um coro permite a participação de um número considerável de indivíduos, o que ratifica a sua vocação social. Ademais, é justamente essa diversidade de corpos e coloridos vocais (timbres) que faz o canto coral ser uma arte tão humanizadora e comovente.

Buscamos a formação de um coletivo artístico, mas priorizamos o aspecto pedagógico do processo. Mais do que um ensaio, pensamos os encontros de estudo como uma aula coletiva de canto ou uma prática de conjunto. Para Claire Dinville (1990, p. 49): “É necessário que o professor de canto tenha um bom conhecimento pedagógico, que possa dar explicações claras e coerentes, bem como exemplos válidos tanto sobre a respiração como sobre o modo de emissão".

As intervenções programadas também compõem o aspecto pedagógico da proposta, lembrando que o ensino de música não pode deixar de trabalhar os aspectos da performance musical (SWANWICK, 2003).

A performance musical é especialmente importante para um coral cênico, pois, como na ópera, tentamos nos aproximar de uma linguagem mais cênica, de uma expressividade dramática que, embora seja ainda muito simples e despretensiosa, desperta no público um encanto todo especial.

\section{Materiais e métodos}

Desenvolvemos as atividades do projeto Coral Cênico UFVJM em duas frentes de trabalho. Primeiro, nos dedicamos à pesquisa de repertório, levando em consideração aspectos técnicos e didáticos. Também preparamos todo o material de apoio a ser utilizado antes de encaminhá-lo aos coralistas. Grande parte das peças escolhidas para o repertório do projeto encontrava-se em péssimas condições de uso, o que nos obrigou a realizar um minucioso trabalho de revisão, transcrição e edição gráfica dos manuscritos originais. Esse trabalho de copista é intenso, mas, ao final do processo, temos em mãos um material visualmente mais acabado, sem contar que podemos manipular com maior liberdade as partes das composições e arranjos, enviando separadamente para cada naipe (SATB) somente as partes que lhe dizem respeito, o que facilita o processo de leitura dos coralistas iniciantes.

Depois, em conjunto com os chefes de naipe, realizamos a gravação de um esboço das peças, que servirá de guia para os coralistas que não dominam o solfejo e, por conseguinte, precisam assimilar as músicas auditivamente através da imitação.

$\mathrm{Na}$ segunda frente de trabalho, realizamos os encontros propriamente ditos, que acontecem uma vez por semana com duração de 95 minutos, embora realizemos também, com alguma regularidade, ensaios de naipe, que são muito produtivos. Os encontros acontecem no Laboratório de Dança (DEFi/ UFVJM), o que impede que façamos um ensaio tradicional, porque não há cadeiras na sala; o uso de pastas e partituras é proibido, a não ser em momentos específicos.

Os encontros de estudo e prática do canto coral são organizados em 6 momentos: 1) Exercícios técnicos de alinhamento, conscientização corporal e harmonização do tônus muscular com base na Eutonia de Gerda Alexander (1991); 2) Deslocamentos espaciais e improvisação gestual com base na Rítmica de Jaques-Dalcroze (JAQUES-DALCROZE, 1916; FINDLAY, 1971, MADUREIRA, 2008); 3) 
Exercícios técnicos de respiração e vocalizes de vibração, ressonância, articulação e extensão realizados com base na tradição do Bel Canto e com base nos estudos de EMMONS e CHASE (2006), FERNANDES (2009) e VACCAI (1990), entre outros; 4) Exercícios de entonação, solfejo e leitura rítmica inspirados nos métodos de Jaques-Dalcroze, Orff e especialmente no "curso elementar" de WILLEMS (1979); 5) Estudo do repertório vocal propriamente dito, observando-se que os encontros não devem ser utilizados como espaço para aprender as peças, mas como um momento para juntar as vozes, harmonizá-las e trabalhar sobre os detalhes técnicos de interpretação e dinâmica; 6) Após termos harmonizado as vozes das peças do repertório, investimos no processo de encenação teatral com base nos estudos de MULLER e FIAMINGHI (2013) e SILVA (2008).

Muitos dos procedimentos metodológicos e referências utilizados nas atividades do Coral Cênico UFVJM tem como base as experiências extraídas de outro projeto de extensão que coordenamos, intitulado "Rítmica Dalcroze e a Formação de Crianças Musicistas", cujos detalhes podem ser consultados no artigo "O ensino da música em debate" (MADUREIRA e MOURA, 2016), publicado no volume 5 deste periódico.

\section{Alguns resultados}

O primeiro encontro do projeto Coral Cênico UFVJM aconteceu em 11/11/2015. Até o presente momento, realizamos 53 encontros oficiais e inúmeros ensaios de naipe e ensaios extras com o coro completo. Iniciamos a proposta com peças em uníssono (Do-re-mi) e cânones a duas vozes (Ciranda em Cânone, O som da Pessoa). Depois, propusemos peças a duas vozes, organizando o coro em vozes masculinas e femininas (Beira-mar/Riacho de areia) e em vozes graves e agudas (Minha canção). Em seguida, experimentamos uma peça a 3 vozes (Cajuína). Com o progressivo amadurecimento musical do grupo, arriscamos a primeira peça a 4 vozes (Amavolovolo) e, desde então, temos investido nas peças para coro misto (SATB). Na tabela 1 é possível observar a ficha técnica de nosso repertório.

\section{Tabela 1 - Repertório do projeto Coral Cênico UFVJM}

\begin{tabular}{|c|c|c|c|c|}
\hline MÚSICA & Compositor & arranjador & forma & PAÍS \\
\hline Do-re-mi & Hammerstein/Rodgers & - & uníssono & EUA \\
\hline Ciranda em Cânone & Gabriel Levy & - & cânone 2 vozes & Brasil \\
\hline Beira-mar/Riacho de areia & Tradição oral brasileira & Nelson Silva & 2 vozes & Brasil \\
\hline O som da pessoa & Gilberto Gil & - & cânone a 2 vozes & Brasil \\
\hline Minha canção & Enriquez/Bardotti/Chico Buarque & - & 2 vozes & Brasil \\
\hline \multirow[t]{2}{*}{ Nos áureos tempos } & Roberto Rodrigues/ & & & \\
\hline & Drummond de Andrade & R. Rodrigues & SATB & Brasil \\
\hline Amavolovolo & Tradição oral Zulu & Rudolf de Beer & SATB & África \\
\hline Cajuína & Caetano Veloso & J. E. Gramani & SAT & Brasil \\
\hline Ay linda amiga & Cancionero del Palacio & Eduardo Torne & SATB & Espanha \\
\hline Climbin'up the Mountain & Tradicional Negro Spiritual & - & SATB & EUA \\
\hline Berimbau & Vinícius de Moraes/Baden Powell & Arlindo Teixeira & SATB & Brasil \\
\hline São Francisco & Vinícius de Moraes/Paulo Soledade & Osvaldo Lacerda & SA & Brasil \\
\hline Pela Luz dos Olhos Teus & Vinícius de Moraes & Paulo Hora & SA & Brasil \\
\hline $\begin{array}{l}\text { Lore-ley } \\
\text { Alemanha }\end{array}$ & H. Heine/F. Silcher & - & SATB & \\
\hline
\end{tabular}

Fonte: Tabela elaborada pelos autores (2017).

Entre as intervenções e performances realizadas pelo Coral Cênico UFVJM, destacamos: 1) Abertura da palestra "Falar e cantar: os cuidados com a voz", realizada no dia 15/12/2016 no Departamento de Educação Física da UFVJM; 2) I Recital do Coral Cênico UFVJM, realizado no dia 17/07/2016 na Igreja do Rosário como parte integrante da programação do I Festival de Inverno de Diamantina (figura 1); 3) Abertura da aula inaugural do Curso Técnico em Teatro do IFNMG, realizada no dia 03/ 08/2016 no Teatro Santa Izabel; 4) Abertura da V Semana de Humanidades da UFVJM, realizada no dia 26/09/2016 no auditório da FIH; 5) Recital de Canto realizado no Centro de Humanidades da UFVJM em 06/04/2017 (figura 2); 6) Encerramento do X Encontro de Educação Física da UFVJM realizado no dia 25/08/2017; 7) Intervenção na Biblioteca da UFVJM (campus JK), realizada em 20/ 08/2017 dentro da programação "Curta o Circuito" promovida pela Diretoria de Cultura da UFVJM. 


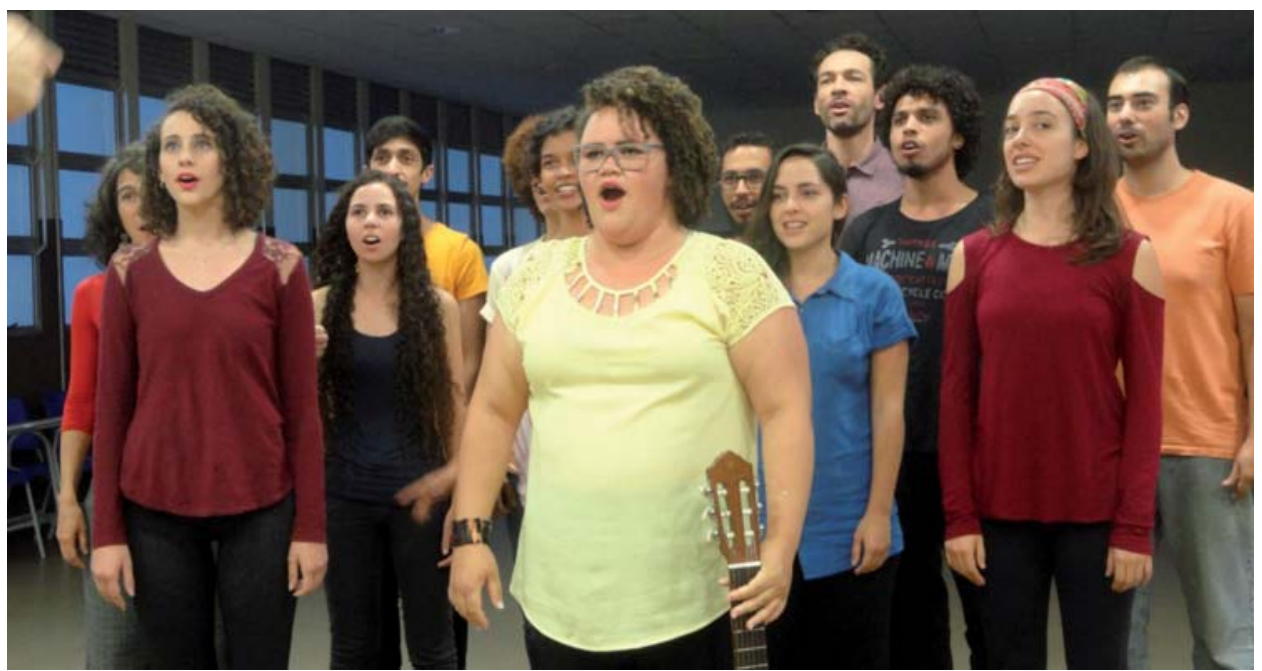

Figura 2 - Recital de Canto realizado no Centro de Humanidades da UFVJM (Diamantina/MG, 06/ 04/2017)

Fonte: Acervo pessoal dos autores

\section{Conclusões}

O maior desafio que encontramos é o grande fluxo de entrada e saída de coralistas, o que não surpreende, pois a maior parte do grupo é formada por estudantes universitários. A cada semestre letivo é preciso reconfigurar o grupo e abrir vagas para novos integrantes, sendo que o processo de seleção de novos coralistas é bastante complexo, consumindo um tempo enorme que, muitas vezes, não alcança os resultados esperados.

De qualquer forma, vivenciamos o projeto Coral Cênico UFVJM como uma grande utopia, porque não há nada que obrigue os coralistas a participar dos ensaios, sendo que eles tampouco se interessam por certificados; o que desejam mesmo é cantar.

A cada performance, os coralistas conquistam um novo patamar artístico, ampliando a sua compreensão sobre os métodos e técnicas de trabalho pedagógico realizadas durante os ensaios. Afinal, sem dedicação e estudo, não há resultado, o que é verdadeiro especialmente no fazer artístico.

Por fim, ainda em ressonância com a meta no 19 do Plano Nacional de Cultura, que indica que "os conteúdos dessas pesquisas deverão estar disponíveis e seus resultados divulgados em sistemas de informação para toda a sociedade". (BRASIL, 2012, p. 62), criamos um site (<coralcenicoufvjm.wordpress.com>) no qual disponibilizamos grande parte do material didático utilizado no projeto para que possa ajudar outros coletivos que desejam "encontrar a felicidade", como diria o grande maestro Heitor Villa-Lobos.

\section{Agradecimentos}

Agradecemos aos cantores Ivanete Pinheiro, Christian Oliveira, Hozanan Leal, Melissa Guimarães e Igor Cardoso pela preciosa gravação dos áudios de apoio destinados aos demais coralistas, como também pela iluminada presença.

\section{Referências Bibliográficas}

ALEXANDER, Gerda. Eutonia: um caminho para a percepção corporal. 2. Ed. São Paulo: Martins Fontes, 1991.

AMATO, Rita Fucci. O canto coral como prática sócio-cultural e educativo-musical. Opus, Goiânia, v.13, n.1, p.75-96, jun. 2007.

ANDRADE, Mário de. Oração de Paraninfo (1935). Pro-Posições, Campinas, v. 16, n. 1 (46), jan./abr. 2005, p. 261-270. 
BRASIL. Ministério da Cultura. As Metas do Plano Nacional de Cultura. Brasília, 2012.

DINVILLE, Claire. A técnica da voz cantada. (tradução de Marjorie Courvoisier Hasson). Rio de Janeiro: Enelivros, 1990.

EMMONS, Shirlee; CHASE, Constance. Prescriptions for choral excellence: tone, text, dynamics leadership. New York: Oxforde University Press, 2006.

FEDERICI, Conrado Augusto Gândara. Giulio Caccini e suas novas músicas: um elogio ao canto. Campinas: Faculdade de Educação da Unicamp, 2009, 182 p. (tese de doutorado em Educação, Linguagem e Arte).

FERNANDES, Angelo José. O regente e a construção da sonoridade coral: uma metodologia de preparo vocal para coros. Campinas: Instituto de Artes da Unicamp, 2009, 483 p. (tese de doutorado em Música).

FINDLAY, Elsa. Rhtythm and Movement: applications of Dalcroze Eurthymics. California: SummyBirchard Inc., 1971.

FONTERRADA, Marisa Trench de Oliveira. De tramas e Fios: um ensaio sobre música e educação. São Paulo: Unesp,/Funarte, 2008.

MADUREIRA, José Rafael. Émile Jaques-Dalcroze: sobre a experiência poética da Rítmica. Campinas: Faculdade de Educação da Unicamp, 2008, 210 p. (tese de doutorado em Educação, Linguagem e Arte).

MADUREIRA, José Rafael e MOURA, Patrícia Coelho de. O ensino de música em debate: uma síntese dos 5 anos do projeto "Rítmica Dalcroze e a Formação de Crianças Musicistas". Viçosa: Elo/diálogos em extensão, v. 5, n. 1, p. 19-28, agosto/2016.

MULLER, Cristiane; FIAMINGHI, Luiz Henrique. Coro Cênico: conceito e discussões. DAPesquisa, v. 1, p. 167-181, 2013.

SILVA, Carlos Alberto. Vozes, Música, Ação: Dalcroze em cena - conexões entre a Rítmica e a encenação. São Paulo: Escola de Comunicação e Arte da USP, 2008, 130 p. (dissertação de mestrado em Práticas Teatrais).

SWANWICK, Keith. Ensinando música musicalmente. (tradução de Alda Oliveira). São Paulo: Moderna, 2003.

VILLA-LOBOS, Heitor. Villa-Lobos por ele mesmo/pensamentos. In: RIBEIRO, João Carlos. (org.). O pensamento vivo de Villa-Lobos. São Paulo: Martin Claret, 1987.

WILLEMS, Edgar. Solfejo: curso elementar (adaptação portuguesa de Raquel Simões). São Paulo: Fermata do Brasil, 1979.

ZANDER, Oscar. A regência coral. 2. Ed. Porto Alegre: Movimento, 2006.

Recebido para publicação em 7/9/2017 e aprovado em 30/10/2017. 